\title{
Prevalence and correlates of Alzheimer's disease and related dementias in rural Uganda: cross-sectional, population-based study
}

Vincent Mubangizi ${ }^{1 *}$ D, Samuel Maling ${ }^{1}$, Celestino Obua ${ }^{1}$ and Alexander C. Tsai ${ }^{1,2}$

\begin{abstract}
Background: There is a paucity of data on the prevalence and correlates of Alzheimer's disease and related dementias in sub-Saharan Africa. The aim of the study was to estimate the prevalence and correlates of Alzheimer's disease and related dementias in rural Uganda.

Methods: We conducted a cross-sectional, population-based study in a rural region of southwestern Uganda. The Brief Community Screening Instrument for Dementia was administered to a multi-stage area probability sample of 400 people aged 60 years and over. Multivariable logistic regression was used to estimate correlates of probable dementia.

Results: Overall, 80 (20\%) of the sample screened positive for dementia. On multivariable regression, we estimated the following correlates of probable dementia: age (adjusted odds ratio [AOR], 1.02 per year; $95 \%$ confidence interval $[C I], 1.10-1.03, p<0.001)$, having some formal education (AOR, $0.57 ; 95 \% \mathrm{Cl}, 0.41-0.81, p=0.001$ ), exercise (AOR, 0.44; $95 \% \mathrm{Cl}, 0.27-0.72, p=0.001)$, and having a ventilated kitchen (AOR, $0.43 ;(95 \% \mathrm{Cl}, 0.24-0.77, p=0.001)$.

Conclusions: In this population-based sample of older-age adults in rural Uganda, nearly one-fifth screened positive for dementia.
\end{abstract}

Keywords: Alzheimer's disease, Dementia, Sub-Saharan Africa, Uganda

\section{Background}

Alzheimer's disease, other dementias, and noncommunicable diseases are likely to impose an increasing burden on health systems throughout sub-Saharan Africa, as country populations age and as communicable disease mortality and morbidity decline $[1,2]$. More than half of all people with dementia are from low- and middle-income countries [1]. A recent report released by Alzheimer's Disease International estimated the ageadjusted dementia prevalence in Sub-Saharan Africa to be $7.2 \%$ among those aged 60 years and over. Globally, a large number of variables have been investigated as potential risk and protective factors for dementia [3], including vascular disease, life style, psychosocial and

\footnotetext{
* Correspondence: vmubangizi@must.ac.ug

${ }^{1}$ Mbarara University of Science and Technology, Mbarara, Uganda Full list of author information is available at the end of the article
}

psychological factors, infectious diseases, genetic factors, and carbon monoxide poisoning.

There are few population-based studies of the prevalence and correlates of dementia in sub-Saharan Africa. The Dementia in Sub-Saharan Africa: Challenges and Opportunities report by Alzheimer's Disease International identified only 12 studies conducted in subSaharan Africa; of these, six were conducted in West Africa, and only one study was conducted in East Africa (Tanzania) [2]. Estimating the population prevalence of Alzheimer's disease and related dementias (AD/RD) in sub-Saharan Africa, and identifying correlates of $\mathrm{AD} /$ $\mathrm{RD}$, has been identified as a public health priority $[2,4]$. To address this gap in the literature, we conducted a population-based study to estimate the prevalence and correlates of Alzheimer's disease and related dementias $(\mathrm{AD} / \mathrm{RD})$ in rural Uganda. 


\section{Methods}

\section{Study design}

We conducted a cross-sectional, population-based study in December 2018 in 16 districts of southwestern Uganda. In this region, the local economy is largely dominated by subsistence agriculture, animal husbandry, and petty trading. Food and water insecurity are common $[5,6]$. People aged 60 years and older comprise approximately $5 \%$ of the total population in the region [7].

Given our study's focus on $\mathrm{AD} / \mathrm{RD}$, we sought to enroll people aged 60 years and older. Study participants were selected using a multi-stage area probability sampling of parishes. In the first stage, using a computerized random number generator, eight districts were selected from a list of 16 districts in southwestern Uganda. In the second stage, one sub-county (or an equivalent administrative local government) was randomly selected from an ordered list of all sub-counties in each of the 8 districts. In the third stage, one parish was randomly selected from each of the selected sub-counties. In each parish, we went door-to-door, recruiting participants consecutively using lists of older-age people that were provided by village health team members, until the required number per parish (50 people) was achieved. Upon approach, potential study participants were asked to confirm their date of birth by furnishing their national identity card. Participants were required to invite a consenting caregiver to answer questions about their activities of daily living. Participants did not need to be literate but were required to hear and see sufficiently well to communicate with study staff, answer survey questions, and undertake cognitive tests.

\section{Survey instrument}

We used the brief Community Screening Instrument for Dementia (CSID), which is suitable for use by nonspecialists in low-resource settings [8]. The screening interview has two sections, with one interview for the person suspected of having dementia, which is used to determine the CSID cognitive score (7 items; range, 0-9, higher score being better); and a separate informant section for a caregiver or close relation, which is used to determine the CSID informant score (6 items; range, $0-6$, higher score being worse). A CSID cognitive score $\leq 4$ suggests probable dementia, a score of 5-6 suggests possible dementia, while a score $\geq 7$ suggests dementia is unlikely. For those with a CSID cognitive score of 5 or 6 suggesting possible dementia, we then interviewed the caregiver/informant. The inclusion of an informant interview is known to enhance the validity of the brief CSID [8]. The CSID informant score was subtracted from the CSID cognitive score to provide the total score (range, -6 to 9). A combined CSID total score (i.e., after subtraction of the informant score from the cognitive score) $\leq 4$ is also suggestive of possible dementia. Thus, study participants may be classified as screening positive for probable dementia in one of two ways: (a) CSID cognitive score $\leq 4$; or (b) CSID cognitive score 5-6 and CSID total score $\leq 4$.

Following screening assessment for dementia, we administered a study questionnaire to elicit other variables, including vascular disease, lifestyle behaviors, psychosocial and psychological factors, infectious disease exposure, and family history. Each variable was enumerated as being either present (yes) or absent (no). Where necessary, a family member provided further clarification during the interview. Study participants' ages were crosschecked with their national identification cards and/or baptism cards. Formal education was defined as the number of years spent in school: none, 1-7 years (primary school), 8-11 years (ordinary level school), and 12 or more years (advanced level and tertiary education). Family history of dementia was elicited with a single self-report item identifying a first-degree relative (sibling or parents) who had ever showed signs of dementia or received a diagnosis of dementia. Lifetime history of cigarette smoking and alcohol consumption were elicited using self-report. High-fat dietary intake was assessed with a single item eliciting a lifetime history of high-fat intake, defined as regular, frequent consumption of animal products (e.g., milk, meat, ghee) or ground nuts during the ages of 25-45 years. Religious integration was defined as participating in religious activities in addition to community prayer. To assess physical activity prior to 60 years of age, we asked a single question about heavy manual labor, riding a bicycle at least three days a week, or engaging in 30 minutes of exercise at least three times a week. Lifetime history of traumatic head injury was defined as ever experiencing head injury accompanied by loss of consciousness. We also elicited lifetime history of syphilis, tuberculosis, human immunodeficiency virus, bacterial meningitis, cerebral malaria, type II diabetes mellitus, cerebrovascular accident, hypertension, epilepsy, limb paralysis, or thyroid condition. Study participants' responses were cross-checked against any medical records kept in the study participants' homes. An adequately ventilated kitchen was defined as one in which the household cooking took place in an open space or one in which there was ventilation from a window or chimney. All study tools were interviewer-administered in the local language (Runyankore-Rukiga). Survey questions were written in English, translated from English into Runyankore-Rukiga, and then back-translated to verify fidelity to the original wording.

\section{Data management and analysis}

Data were entered, cleaned, and analyzed using Epi Info version 7.2.2.6. As described above, the brief CSID provides an estimate of the screening prevalence of 
dementia. In most settings, the screening prevalence of dementia likely exceeds the true prevalence of dementia, due to the nonzero false positive rate. While the true prevalence of dementia is unknowable in the absence of data from a criterion standard (i.e., clinical diagnosis made on the basis of a structured clinical interview), we followed the "back estimation" method described by de Jager et al. [9] to estimate the prevalence of dementia based on our screening data and the known sensitivity (0.95) and specificity (0.90) of the brief CSID [8]. First, we estimated the number of true positives (TP) given the well-known relationships between sensitivity (SE)/ specificity (SP) and the number of test positives (testp) and test negatives (testn):

$$
T P=\frac{\text { testp }-\left(\text { testn } \times \frac{1-S P}{S P}\right)}{1-\left(\frac{1-S P}{S P} \times \frac{1-S E}{S E}\right)}
$$

We then used the estimated number of true positives to calculate the estimated prevalence rate.

We compared the proportions of those with probable dementia across different subgroups using the chisquare test. All variables with a statistically significant association with probable dementia on bivariate analysis were entered as potential covariates in a multivariable logistic regression model specifying probable dementia as the dependent variable.

\section{Ethics approval and consent to participate}

Ethical approval to conduct this study was obtained from the Mbarara University of Science and Technology Research Ethics Committee (reference number 13/10-18). Consistent with national guidelines, clearance for the study was granted by the Uganda National Council for Science and Technology (reference number SS 4842). We obtained administrative permission to enter the study communities from the district administrative head at each site. All study participants (informants and caregivers) provided written informed consent to participate. If a signature could not be obtained for literacy reasons, verbal informed consent was obtained in the presence of a witness, and the study participant was permitted to indicate a signature using a thumbprint. For study participants who could not provide informed consent due to cognitive difficulties (e.g., presumed dementia), informed consent to participate was obtained from a caregiver, and the study participant was permitted to provide assent. All participants who screened positive dementia were referred to the nearest hospital (Mbarara Regional Referral Hospital, Kabale Regional Referral Hospital, Rugarama Hospital [Kabale], Kisiizi Hospital [Rukungiri], Nyakibale Hospital [Rukungiri], Itojo Hospital [Ntungamo], Kitagata General
Hospital [Sheema], Kampala International University Teaching Hospital [Ishaka], or Ishaka Adventist Hospital [Ishaka]) for further clinical assessment and management.

\section{Results}

Characteristics of the study sample

A total of 400 index participants along with 400 caregivers ("informants") were interviewed. All potential participants approached by our team for interviews agreed to participate. Summary statistics are provided in Table 1 (all percentages may not add up to 100 due to rounding). The mean age of the index participant sample was 72 years (range, 60-108 years). In comparison, the informant/caregiver sample had a mean age of 34 years (range, 13-78 years). Most index participants (238 [60\%]) and informants $(263$ [66\%]) were women. Nearly all informants were biologically related to the index participants.

\section{Prevalence of dementia}

Among the 400 index participants, the median CSID cognitive score was 7 (interquartile range [IQR], 6-9), and 23 (5.8\%) had a CSID cognitive score $\leq 4$. Another 103 (26\%) index participants had a CSID cognitive score of 5 or 6 . For these 103 participants, a caregiver or close relative was interviewed; the median CSID informant score was 3 (IQR, 2-4), and 83/103 (81\%) had a CSID total score $\leq 4$. Caregivers most frequently reported that index participants had problems with 'forgetting where they have put things' (250 [63\%]), 'general decline in mental functioning' (223 [56\%]), 'ability to think and reason' (158 [40\%]), and 'remembering what they did the day before' (117 [29\%]). Caregivers were least likely to report that index participants had 'difficulties with dressing' (71 [18\%]).

The total number of index participants who screened positive for probable dementia, on the basis of either the CSID cognitive score or the CSID informant score, was $23+83=106(27 \%)$. Using the back-estimation method described above, the estimated number of true positives was 78 , for an estimated prevalence rate of $78 / 400=20 \%$.

\section{Correlates of probable dementia}

Correlates of probable dementia are shown in Table 2. On bivariate analysis, statistically significant correlates of probable dementia included age, education, religious activity, having an adequately ventilated kitchen, and physical activity. When the candidate covariates were entered simultaneously into a multivariable logistic regression model, all retained a statistically significant association with probable dementia except for religious activity. Probable dementia was positively correlated with age (adjusted odds ratio $[\mathrm{AOR}]=1.02 ; 95 \%$ confidence interval $[\mathrm{CI}], 1.01-1.03)$ and was negatively correlated with education ( $\mathrm{AOR}=0.68$; 95\% CI, 0.49-0.96), having an adequately ventilated kitchen $(\mathrm{AOR}=0.43 ; 95 \% \mathrm{CI}$, 
Table 1 Socio-demographic characteristics of index participants $(N=400)$ and informants $(N=400)$

\begin{tabular}{|c|c|c|c|}
\hline & Variable & Number & Percent \\
\hline \multicolumn{4}{|l|}{ Index participants $(N=400)$} \\
\hline Age in years, mean (SD) & & $72(9.5)$ & \\
\hline \multirow[t]{2}{*}{ Sex } & Men & 162 & 41 \\
\hline & Women & 238 & 60 \\
\hline \multirow[t]{4}{*}{ Formal education } & None & 180 & 45 \\
\hline & Primary & 175 & 44 \\
\hline & Ordinary level & 19 & 4.8 \\
\hline & Advanced level and above & 26 & 6.5 \\
\hline \multirow[t]{4}{*}{ Marital status } & Married & 207 & 52 \\
\hline & Separated/Divorced & 29 & 7.3 \\
\hline & Widowed & 155 & 39 \\
\hline & Never married & 9 & 2.3 \\
\hline \multirow[t]{2}{*}{ Religion } & Christian & 343 & 86 \\
\hline & Muslim & 57 & 14 \\
\hline \multicolumn{4}{|l|}{ Informants $(N=400)$} \\
\hline \multirow[t]{6}{*}{ Relationship to index participant } & Spouse & 46 & 12 \\
\hline & Sibling & 9 & 2.3 \\
\hline & Child & 144 & 36 \\
\hline & Grandchild & 116 & 29 \\
\hline & Other relative & 62 & 16 \\
\hline & Not biologically related & 23 & 5.8 \\
\hline Age in years, mean (SD) & & $34(15)$ & \\
\hline \multirow[t]{2}{*}{ Sex } & Men & 137 & 34 \\
\hline & Women & 263 & 66 \\
\hline \multirow[t]{5}{*}{ Years of formal education } & None & 46 & 12 \\
\hline & Primary & 170 & 43 \\
\hline & Ordinary level & 139 & 35 \\
\hline & Advanced level and above & 44 & 11 \\
\hline & Not answered & 1 & 0.3 \\
\hline
\end{tabular}

$0.24-0.77$ ), and physical activity $(\mathrm{AOR}=0.44 ; 95 \% \mathrm{CI}$, $0.27-0.72)$.

\section{Discussion}

In this population-based study of 400 older-age adults from rural Uganda, we estimated the population prevalence of dementia to be $20 \%$. This estimated prevalence is higher than the $8 \%$ estimated prevalence rate reported in a recently published community-based survey from South Africa, which had a similar age distribution of study participants and used a similar screening instrument (i.e., the brief CSID) [9]. Notably, in our study, nearly $80 \%$ of positive dementia screens were categorized as such due to the informant/caregiver score, which exceeds the 30\% reported by de Jager et al. [9]. The difference in prevalence rates between our study and de Jager's study is therefore due to differences in the distribution of informant scores.
Assessment tools which incorporate an informant interview, like the CSID, can be affected by the reliability of the informant. In our study, informants provided relatively high scores. In addition, the involvement of village health team members in mobilizing study participants could have led informants to anticipate aid from study investigators and thereby provide exaggerated responses.

Our estimate of dementia prevalence also exceeds the rate of $6.4 \%$ obtained by Longdon et al. in Tanzania, which had an older age distribution but which also used the full CSID and Diagnostic and Statistical Manual of Mental Disorders (fourth edition) criteria to obtain clinical diagnoses [10]. Thus, the observed discrepancy between the Longdon et al. study and ours is to be expected, given that screening instruments generally yield high prevalence estimates compared with structured clinical interviews (which is generally the case for depression [11, 12]). In addition, as argued by 
Table 2 Correlates of probable dementia, based on bivariate analysis and multivariable logistic regression

\begin{tabular}{|c|c|c|c|c|c|c|}
\hline & $\mathrm{N}$ & Percent & OR $(95 \% \mathrm{Cl})$ & $P$-Value & AOR $(95 \% \mathrm{Cl})$ & $P$-Value \\
\hline \multicolumn{7}{|l|}{ Sociodemographic factors } \\
\hline Age (years) & 400 & & $0.99(0.99-0.99)$ & $<0.001$ & $1.02(1.01-1.03)$ & $<0.001$ \\
\hline Male (vs. female) & 162 & 26 & $0.91(0.58-1.44)$ & 0.69 & & \\
\hline Formal education (yes/no) & 220 & 20 & $0.43(0.27-0.67)$ & $<0.001$ & $0.68(0.49-0.96)$ & 0.03 \\
\hline Christian (vs. Muslim) & 343 & 28 & $1.27(0.67-2.51)$ & 0.44 & & \\
\hline Religiously active (yes/no) & 183 & 19 & $0.45(0.28-0.71)$ & $<0.001$ & $0.63(0.38-1.05)$ & 0.08 \\
\hline Household cooking done with firewood (vs. charcoal) & 390 & 27 & $0.67(0.14-3.21)$ & 0.89 & & \\
\hline Adequate ventilation of kitchen (yes/no) & 329 & 24 & $0.47(0.27-0.81)$ & 0.01 & $0.43(0.24-0.77)$ & 0.004 \\
\hline \multicolumn{7}{|l|}{ Vascular factors } \\
\hline Hypertension (yes/no) & 125 & 32 & $1.43(0.90-2.28)$ & 0.13 & & \\
\hline Cerebrovascular accident (yes/no) & 17 & 35 & $1.50(0.54-4.17)$ & 0.43 & & \\
\hline Diabetes mellitus (yes/no) & 38 & 21 & $0.71(0.31-1.59)$ & 0.40 & & \\
\hline \multicolumn{7}{|l|}{ Behavioral factors } \\
\hline High-fat diet during middle age (yes/no) & 209 & 28 & $1.08(0.70-1.69)$ & 0.72 & & \\
\hline Physically active (yes/no) & 246 & 19 & $0.34(0.22-0.54)$ & $<0.001$ & $0.44(0.27-0.72)$ & 0.001 \\
\hline Cigarette smoking (yes/no) & 183 & 27 & $1.03(0.66-1.60)$ & 0.89 & & \\
\hline Alcohol use (yes/no) & 233 & 26 & $0.90(0.57-1.40)$ & 0.64 & & \\
\hline \multicolumn{7}{|l|}{ Infectious factors } \\
\hline Human immunodeficiency virus (yes/no) & 7 & 43 & $2.06(0.45-9.35)$ & $0.60^{*}$ & & \\
\hline Meningitis (yes/no) & 12 & 33 & $1.38(0.41-4.68)$ & 0.60 & & \\
\hline Cerebral malaria (yes/no) & 28 & 32 & $1.31(0.57-2.98)$ & 0.53 & & \\
\hline Syphilis (yes/no) & 66 & 24 & $0.84(0.46-1.55)$ & 0.58 & & \\
\hline Tuberculosis (yes/no) & 15 & 40 & $1.85(0.64-5.33)$ & 0.25 & & \\
\hline \multicolumn{7}{|l|}{ Other factors } \\
\hline Traumatic head injury (yes/no) & 27 & 30 & $1.15(0.49-2.71)$ & 0.75 & & \\
\hline Limb paralysis (yes/no) & 204 & 26 & $0.90(0.58-1.40)$ & 0.64 & & \\
\hline Epilepsy (yes/no) & 9 & 56 & $3.50(0.93-13.3)$ & $0.12^{*}$ & & \\
\hline Thyroid condition (yes/no) & 14 & 21 & $0.73(0.20-2.67)$ & 0.86 & & \\
\hline Family history of dementia (yes/no) & 80 & 20 & $0.62(0.34-1.13)$ & 0.11 & & \\
\hline
\end{tabular}

*Yates $P$ value

Paddick et al., the CSID screening process generally produces higher prevalence estimates compared with structured clinical interviews possibly due to the detection of early dementia and mild cognitive impairment [13].

Our study identified several independent correlates of probable dementia. As expected, advancing age had a statistically significant positive correlation with probable dementia, similar to what has been demonstrated in other studies $[9,10,14]$. Also consistent with prior work, formal education was inversely associated with probable dementia [13-15], although this association has not been universally observed $[9,10,16]$. Although there were high levels of illiteracy in our study and thede Jager et al. study, formal education was inversely associated with probable dementia in our study whereas it did not have the same association in the de Jager study [9]. This difference could be due to differences in informal lifestyle choices shaped by culture that are thought to be protective against cognitive decline.

Physical activity, which we found to be inversely associated with probable dementia, has not been widely studied in relation to brain health in sub-Saharan Africa. Finally, we also found that having an adequately ventilated kitchen had an independent, inverse association with probable dementia. Air pollution is a growing problem globally [17] and has been linked, in studies from Uganda, to other health problems like respiratory symptoms $[18,19]$. One population-based study from Taiwan found that higher levels of carbon monoxide exposure were significantly associated with an increased risk of dementia [20]. People in rural Uganda may be exposed to indoor air pollution when they sit around the fire for 
warmth during the evenings or when they prepare their meals in inadequately ventilated kitchens. Prior work by Saenz et al. has identified an inverse association between indoor air pollution and cognitive function [21].

Interpretation of our findings is subject to several limitations. First, due to limited resources, we could not obtain clinical diagnoses of dementia using structured clinical interviews. Because we used the brief CSID, we may have overestimated the prevalence of dementia, given that screening instruments generally produce higher prevalence estimates due to the detection of early dementia and mild cognitive impairment. However, the brief CSID has shown strong evidence of validity in screening for dementia, and we used the backestimation method described by de Jager et al. [9] which revised downward the estimated prevalence. A second limitation is that early and midlife exposure variables were measured with self-report. Cognitive impairment could have caused study participants to recall these variables with error.

These limitations notwithstanding, understanding the prevalence and correlates of $\mathrm{AD} / \mathrm{RD}$ in a resourceconstrained setting like Uganda is critical for creating public awareness, influencing policy recommendations, and developing effective interventions.

\section{Conclusions}

In this population-based sample of older-age adults, nearly one-fifth screened positive for dementia. We found a relatively high prevalence of dementia compared with studies conducted elsewhere in sub-Saharan Africa. Further studies are needed to establish the reasons underlying this discrepancy, which could have resulted from artefact, or from better case finding, longer survival of persons with dementia, and/or regional differences in the epidemiology of dementia and cognitive impairment. In addition, further studies to determine the primary causes and subtypes of dementia need to be done to inform specific risk-focused interventions.

\footnotetext{
Abbreviations

AD/RD: Alzheimer's disease and related dementias; AOR: Adjusted odds ratio; $\mathrm{Cl}$ : Confidence interval; CSID: Community Screening Instrument for Dementia; IQR: Interquartile range
}

\section{Acknowledgements}

We are grateful to the participants, their caregivers, research assistants, and the district leadership from the six districts of Rubanda, Kabale, Rukiga, Ntungamo, Mbarara, Ibanda, Sheema, and Bushenyi, for their time and assistance with data collection. This study was funded by the U.S. National Institutes of Health $(\mathrm{NIH})$ through the Mbarara University Alzheimer's Disease and Related Dementias Research Initiative (MADRI) (D43TW010128-04S1). We would also like to acknowledge the MADRI technical team for their support. ACT reports salary support from R01MH113494.

\section{Authors' contributions}

VM conceptualized the study, collected and analyzed the data, and drafted the manuscript. SM and CO participated in conceptualization of the study, interpretation of data analysis, and reviewed drafts of the manuscripts. ACT participated in interpretation of the data analysis and reviewed drafts of the manuscripts. All authors read and approved the final manuscript.

\section{Authors' information}

VM is a MADRI research fellow and is a Lecturer at the Mbarara University of Science and Technology in Mbarara, Uganda.

SM is Associate Professor of Psychiatry at the Mbarara University of Science and Technology. He is the Program Director of the Mbarara Alzheimer's and Related Dementias Research Initiative (MADRI) program.

$\mathrm{CO}$ is Professor of Pharmacology at the Mbarara University of Science and Technology. He is the Program Director of MADRI.

ACT is a psychiatrist at the Massachusetts General Hospital, Associate Professor of Psychiatry at Harvard Medical School, and an Honorary Lecturer at the Mbarara University of Science and Technology.

\section{Funding}

Research reported in this publication was supported by the Fogarty International Center and the National Institute on Aging of the U.S. National Institutes of Health, under grant number D43TW010128-04S1. ACT reports salary support from R01113494. The sponsors of this study had no role in designing the study; in the collection, analysis, and interpretation of data; in the writing of the report; or in the decision to submit the paper for publication.

\section{Availability of data and materials}

The full dataset generated and analyzed during the current study are not publicly available in order to maintain the privacy of the individuals interviewed during this study. De-identified data can be made available by the corresponding author on reasonable request.

\section{Ethics approval and consent to participate}

Ethical approval to conduct this study was obtained from the Mbarara University of Science and Technology Research Ethics Committee (reference number 13/10-18). Consistent with national guidelines, clearance for the study was granted by the Uganda National Council for Science and Technology (reference number SS 4842). We obtained administrative permission to enter the study communities from the district administrative head at each site. All study participants (informants and caregivers) provided written informed consent to participate. If a signature could not be obtained for literacy reasons, verbal informed consent was obtained in the presence of a witness and the study participant was permitted to indicate a signature using a thumbprint. For study participants who could not provide informed consent due to cognitive difficulties (for example, presumed dementia), informed consent to participate was obtained from a caregiver, and the study participant was permitted to provide assent. All participants who screened positive dementia were referred to the nearest hospital (Mbarara Regional Referral Hospital, Kabale Regional Referral Hospital, Rugarama Hospital [Kabale], Kisiizi Hospital [Rukungiri], Nyakibale Hospital [Rukungiri], Itojo Hospital [Ntungamo], Kitagata General Hospital [Sheema], Kampala International University Teaching Hospital [Ishaka], or Ishaka Adventist Hospital [lshaka]) for further clinical assessment and management.

\section{Consent for publication}

Written permission to publish the findings was sought from all participants, who were assured of anonymity and confidentiality in reporting.

\section{Competing interests}

The authors declare that they have no competing interests.

\section{Author details}

${ }^{1}$ Mbarara University of Science and Technology, Mbarara, Uganda. ${ }^{2}$ Massachusetts General Hospital and Harvard Medical School, Boston, MA, USA.

Received: 23 September 2019 Accepted: 6 February 2020

Published online: 10 February 2020

\section{References}

1. Prince M, Wimo A, Guerchet M, Ali G-C, Wu Y-T, Prina M. World Alzheimer report 2015: the global impact of dementia; an analysis of prevalence, incidence, cost and trends. London: Alzheimer's Disease International; 2015. 
2. Guerchet $M$, Mayston $R$, Lloyd-Sherlock P, Prince M, Aboderin I, Akinyemi R, Paddick S-M, Wimo A, Amoakoh-Coleman M, Uwakwe R, Ezeah P. Dementia in sub-Saharan Africa: challenges and opportunities. London: Alzheimer's Disease International; 2017.

3. Prince M, Albanese E, Guerchet M, Prina M. World Alzheimer report 2014: dementia and risk reduction; an analysis of protective and modifiable factors. London: Alzheimer's Disease International; 2014.

4. Wortmann M. Dementia: a global health priority -highlights from an ADI and World Health Organization report. Alzheimers Res Ther. 2012;4:40.

5. Tsai AC, Bangsberg DR, Frongillo EA, Hunt PW, Muzoora C, Martin JN, et al. Food insecurity, depression and the modifying role of social support among people living with HIV/AIDS in rural Uganda. Soc Sci Med. 2012;74(12):2012-9.

6. Tsai AC, Kakuhikire B, Mushavi R, Vořechovská D, Perkins JM, McDonough $A Q$, et al. Population-based study of intra-household gender differences in water insecurity: reliability and validity of a survey instrument for use in rural Uganda. J Water Health. 2016;14(2):280-92.

7. Uganda Bureau of Statistics. The national population and housing census 2014-main report. Kampala: Uganda Bureau of Statistics; 2016.

8. Prince $M$, Acosta $D$, Ferri CP, Guerra M, Huang $Y$, Jacob KS, Libre Rodriguez JJ, Salas A, Sosa AL, Williams JD, Hall KS, 10/66 Dementia Group. A brief dementia screener suitable for use by non-specialists in resource poor settings-the cross-cultural derivation and validation of the brief community screening instrument for dementia. Int J Geriatr Psychiatry. 2011;26:899-907.

9. de Jager CA, Msemburi W, Pepper K, Combrinck MI. Dementia prevalence in a rural region of South Africa: a cross-sectional community study. J Alzheimers Dis. 2017;60:1087-96.

10. Longdon AR, Paddick S, Kisoli A, Dotchin C, Gray WK, Dewhurst F, Chaote P, Teodorczuk A, Dewhurst M, Jusabani AM, Walker R. The prevalence of dementia in rural Tanzania: a cross-sectional community-based study. Int J Geriatr Psychiatry. 2013;28:728-37.

11. Tsai AC. Reliability and validity of depression assessment among persons with HIV in sub-Saharan Africa: systematic review and meta-analysis. J Acquir Immune Defic Syndr. 2014;66(5):503-11.

12. Kagere A, Tsai A, Lund C, Tomlison M. Screening for common mental disorders in low resource settings: reasons for caution and a way forward. Int Health. 2013;5(1):11-4.

13. Paddick SM, et al. Dementia prevalence estimates in sub-Saharan Africa: comparison of two diagnostic criteria. Glob Health Action. 2013;6(1):19646.

14. Toure KCM, Ndiaye M, Zunzunegui MV, Bacher Y, Diop AG, Ndiaye MM. Risk factors for dementia in a Senegalese elderly population aged 65 years and over. Dement Geriatric Cogn Dis. 2012;2:160-8.

15. Akinyemi RO, Allan L, Owolabi MO, Akinyemi JO, Ogbole G, Ajani A, Firbank M, Ogunniyi A, Kalaria RN. Profile and determinants of vascular cognitive impairment in African stroke survivors: the CogFAST Nigeria Study. J Neurol Sci. 2014;346(1-2):241-9.

16. Guerchet M, Mouanga A, M'Belesso P, Tabo A, Bandzouzi B, Paraiso MN, Houinato DS, Cowppli-Bony P, Nubukpo P, Aboyans V, Clément JP, Dartigues JF, Preux PM. Factors associated with dementia among elderly people living in two cities in Central Africa: the EDAC multicenter study. J Alzheimers Dis. 2012;29(1):15-24.

17. Landrigan PJ, Fuller R, Acosta NJR, Adeyi O, Arnold R, Basu N, Bald'e AB, Bertollini R, Bose-O'Reilly S, Boufford JI, Breysse PN, Chiles T, Mahidol C, CollSeck AM, Cropper ML, Fobil J, Fuster V, Greenstone M, Haines A, Hanrahan D, Hunter D, Khare M, Krupnick A, Lanphear B, Lohani B, Martin K, Mathiasen KV, McTeer MA, Murray CJL, Ndahimananjara JD, Perera F, Potǒcnik J, Preker AS, Ramesh J, Rockström J, Salinas C, Samson LD, Sandilya K, Sly PD, Smith KR, Steiner A, Stewart RB, Suk WA, van Schayck OCP, Yadama GN, Yumkella K, Zhong M. The Lancet Commission on pollution and health. Lancet. 2018 Feb 3;391(10119):462-512.

18. North CM, Kakuhikire B, Vořechovská D, Hausammann-Kigozi S, McDonough AQ, Downey J, Christiani DC, Tsai AC, Siedner MJ. Prevalence and correlates of chronic obstructive pulmonary disease and chronic respiratory symptoms in rural southwestern Uganda: a cross-sectional, population-based study. J Glob Health. 2019;9(1):010434.

19. North CM, Valeri L, Hunt PW, Mocello AR, Martin JN, Boum Y 2nd, Haberer JE, Bangsberg DR, Christiani DC, Siedner MJ. Cooking fuel and respiratory symptoms among people living with HIV in rural Uganda. ERJ Open Res. 2017:3(2):00094-2016.
20. Chang KH, Chang M, Muo CH, Wu TN, Chen CY, Kao CH. Incresased risk of dementia in patients exposed to nitrogen dioxide and carbon monoxide: a population-based retrosepective cohort study. PLoS One. 2014;9:e103078.

21. Saenz $J \mathrm{~L}$, Wong $\mathrm{R}$, Ailshire JA. Indoor air pollution and cognitive function among older Mexican adults. J Epidemiol Community Health. 2018;72:21-6.

\section{Publisher's Note}

Springer Nature remains neutral with regard to jurisdictional claims in published maps and institutional affiliations.
Ready to submit your research? Choose BMC and benefit from:

- fast, convenient online submission

- thorough peer review by experienced researchers in your field

- rapid publication on acceptance

- support for research data, including large and complex data types

- gold Open Access which fosters wider collaboration and increased citations

- maximum visibility for your research: over $100 \mathrm{M}$ website views per year

At BMC, research is always in progress.

Learn more biomedcentral.com/submissions 